\title{
Multiple point electrical stimulation of ulnar and median nerves
}

\author{
H. A. K A D R I E, S. K. YA T E S, H. S. M I L N E R - B R O W N, \\ A N D W. F. B R O W N ${ }^{1}$ \\ From the Department of Clinical Neurological Sciences, \\ University Hospital, London, Ontario, Canada
}

SYNOPSIS A computer-assisted method of isolating single motor units (MUs) by multiple point stimulation (MPS) of peripheral nerves is described. MPS was used to isolate 10-30 single MUs from thenar and hypothenar muscles of normal subjects and patients with entrapment neuropathies, with the original purpose of obtaining a more representative mean motor unit potential for estimating the number of MUs in a muscle. The two important results that evolved from MPS however, were: (1) in the absence of 'alternation' MUs were recruited in an orderly pattern from small to large, and from longer to shorter latencies by graded electrical stimulation in both normal and pathological cases, (2) a comparison of the sizes of MUs recruited by stimulation proximal and distal to the elbow suggested that axonal branching can occur in the forearm $200 \mathrm{~mm}$ or more proximal to the motor point in intrinsic hand muscles.

It was recently suggested that multiple point electrical stimulation along peripheral nerves could be used as an alternative method of obtaining a large and more representative sample of motor units, in the estimation of motor unit numbers (Brown and Milner-Brown, 1976). This method was suggested in an attempt to eliminate the inherent problem of 'alternation' that affected all previous methods (McComas et al., 1971; Brown, 1972, 1973; Sica et al., 1974; Ballantyne and Hansen, 1974; Panayiotopoulos et al., 1974; Brown et al., 1974; Milner-Brown and Brown, 1976). With the aid of laboratory computer, the method of multiple point stimulation (MPS) has been used to isolate 10-30 motor units, exclusive of alternation, from the thenar and hypothenar muscles of 19 normal subjects and nine patients with entrapment neuropathies.

Multiple point stimulation (MPS) led to interesting statistically supportable evidence bearing on the question of the rank order of activation of motor units by electrical stimulation, a subject on

\footnotetext{
${ }^{1}$ Address for correspondence: Dr W. F. Brown, Department of Clinical Neurological Sciences, University Hospital, 339 Windermere Road, London, Ontario, Canada N6G 2K3.

(Accepted 7 May 1976.)
}

which previous evidence has been in conflict. The contention that graded electrical stimulation of a nerve activates first the largest diameter fibres has been based on the observation that in sensory nerves the shortest latency fibres have the lowest threshold (Erlanger and Gasser, 1973; Tasaki, 1939). That this assumption may not be applicable in the case of nerve fibres of uniform functional fibre type (motor axons), particularly in the case of humans, has been suggested by evidence that the first motor axons excited have had the longest latencies from the point of stimulation to the initial deflection of the evoked potential recorded from the muscle using surface electrodes (Hodes et al., 1965; Bergmans, 1970). This question of the excitability order of motor axons made it necessary also to examine the relationship of motor unit size to latency.

Multiple point stimulation helped to extend the understanding of the limitations of electrical stimulation of motor nerves by testing for exclusion of the larger motor units (MUs) by comparing MUs isolated by isometric contraction with MUs isolated using MPS and quantitating the degree of overlap in the firing levels of the first one to five motor axons.

Finally, MPS has been used to compare the 
sizes of motor units evoked by stimulation at proximal $v s$ distal points along the length of the nerve. Earlier evidence based on histological (Eccles and Sherrington, 1930; Wray, 1969) and axon reflex (Fullerton and Gilliatt, 1965), investigations had led to the contention that little or no significant axon branching occurs $150 \mathrm{~mm}$ proximal to the motor point in healthy human motor nerves. On the contrary, in this investigation, evidence of a progression from smaller to larger mean motor unit potential sizes as much as 200 $400 \mathrm{~mm}$ proximal to the motor point suggested the possibility of more proximal axon branching, and one more limitation in the use of distal motor nerve stimulation in the estimation of mean motor unit potential sizes.

This paper therefore deals with (1) the mean motor unit potentials of $10-30$ MUs isolated from normal subjects and patients with peripheral neuropathies using the method of MPS of peripheral nerves, (2) the rank order of recruitment of MUs during graded electrical stimulation, and (3) the extent of axonal branching along peripheral nerves.

\section{METHODS}

\section{SUBJECTS}

Four groups of volunteers were obtained. Group 1 , the 'ulnar control group', consisted of 19 healthy volunteers with a mean age of 26 (2037) years. Group 2, the 'median control group', consisted of 12 healthy volunteers with a mean age of $27(20-45)$ years. Most of the control subjects were medical students and residents in the Department of Neurology, with no history or clinical evidence of neurological disease. Group 3 , the 'ulnar pathological group', consisted of nine volunteers with a mean age of 43 (21-62) years. All had previously had anterior ulnar nerve transpositions because of ulnar nerve compression at the elbow. Group 4, the 'median pathological group', consisted of nine volunteers, mean age of 53 (40-75) years, who had previously had carpal tunnel releases performed because of median nerve entrapment at the wrist.

\section{ELECTROPHYSIOLOGICAL TESTS}

The muscles investigated included the thenar and hypothenar groups using experimental arrangements that have been described in detail before (Feasby and Brown, 1974; Brown and MilnerBrown, 1976). The new modification introduced in this report has been to stimulate the respective motor nerves at 10 to 20 points along the length of the nerve from the level of the wrist to the upper arm. The underlying nerve was stimulated using percutaneous electrodes and brief $(0 \cdot 05-0 \cdot 1$ ms) electrical pulses at a frequency less than $1 / \mathrm{s}$. The stimulus voltage was increased in a graded manner until the first and subsequent motor units were, in turn, excited in an all or nothing manner, only MUs having distinct thresholds - that is, no alternation-being accepted in the motor unit sample (Brown and Milner-Brown, 1976). Electrical stimulation was carried out at enough points to obtain at least 10 to 30 distinct MUs from the hypothenar or thenar muscles in each person.

\section{COMPUTER ANALYSIS}

An on-line Hewlett-Packard 2100 computer was used to measure the peak to peak voltage (p-pV), area (in $\mathrm{mV}$. ms) full wave rectified, latency to initial deflection of the potentials of single MUs, and of the maximum compound potentials of the respective muscles. In general, changes in area paralleled changes in $\mathrm{p}-\mathrm{pV}$ and therefore only the $\mathrm{p}-\mathrm{pVs}$ of MUs have been included in the Tables Latencies could be measured accurately to within $0.05 \mathrm{~ms}$. Motor unit potential parameters werep measured by subtraction of the averaged 'nothing? oriented response at the critical firing level of the motor unit from the averaged 'all' response (Fig. 1).

Measurement of the MU parameters by subse traction was made necessary because the baseline was not ' 0 ' but frequently distorted by artefact from the stimulus or contraction of the proximal muscles, the latter occurring in the case of stimulation of the motor nerves in the upper arm.

The question of the frequency of overlap of motor unit firing levels at each point of stimulation was investigated by counting the number of times that $0,1,2 \ldots 5$ MUs could be activated, in order, exclusive of alternation using trains of constant intensity stimuli (Brown and MilnerBrown, 1976).

\section{STATISTICAL ANALYSIS}

The order in which motor units were activated in terms of amplitude (p-pV), area, and latency by electrical stimulation was statistically analysed by two methods. In the first, the significance of the correlation between amplitude, area or latency and the order of activation, was tested using Kendall's 'rank correlation methods' (1962) as applied by Henneman et al. (1965). The method is independent of the absolute values of the parameters and is based on the comparison of the rank orders in pairs. To this end, the data were 


\section{AVERAGER DISPLAY}

$M U_{1}$

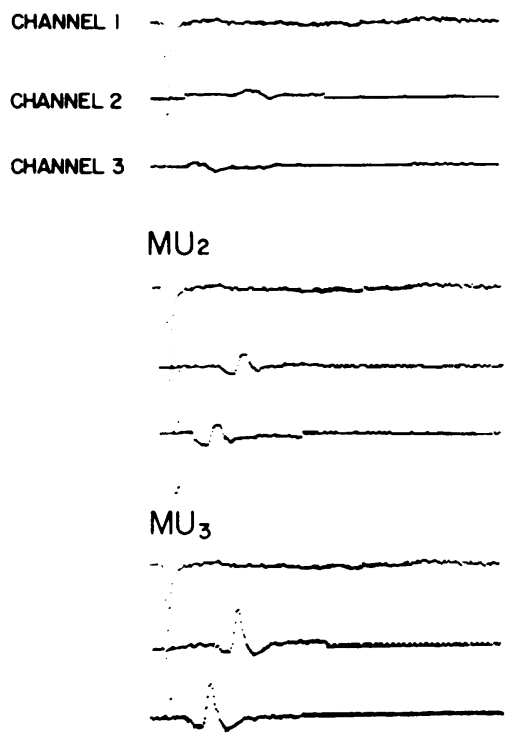

STORAGE OSCILLOSCOPE DISPLAY

$\mathrm{MU}_{1}$

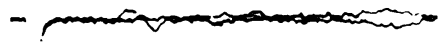

$\mathrm{MU}_{2}$

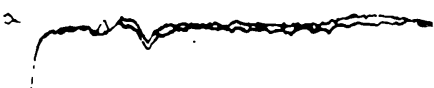

$\mathrm{MU}_{3}$

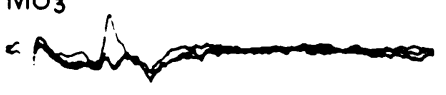

FIG. 1 The computer results displayed on the HP 5480 averager display, with the corresponding analogue display on a storage oscilloscope. On the averager display, channel 1 is merely used as the input channel to the computer. Channels 2 and 3 show the results obtained from the computer. Channel 2 shows the individual MU obtained by subtracting out all other MUs from the composite potential and averaging the result to eliminate noise. Channel 3 shows the extracted MU on channel 2 shifted to its point of initial deflection. Channel 3 was displayed to provide a visual check that the computer had recognised the point of initial deflection and hence had calculated the correct latency.

arranged in sets 2,3 , or 4 units corresponding to the maximum number of motor units that could be activated, free of alternation at each point. Motor units in each set were ranked $\mathbf{M U}_{1}$. . $\mathrm{MU}_{2} \ldots \mathrm{MU}_{\mathrm{n}}$ in the order of activation and compared with the ranked order of increasing $\mathrm{p}-\mathrm{pV}$, area, and decreasing latency. $A+1,-1$, or $\pm \frac{1}{2}$ score was assigned depending upon whether, for example, the $\mathrm{p}-\mathrm{pV}$ of $\mathrm{MU}_{1}$ (the first unit activated) was less than, greater than, or equal to the $\mathrm{p}-\mathrm{pV}$ of $\mathrm{MU}_{2}$ (the second unit recruited). For each set and for all the observations for each parameter the total number of positive or negative scores was determined, and the statistical significance of the differences tested, using Student's $t$ test.
In the second method, the means \pm 1 SD of the parameters of the MUs activated first, second, and so on were calculated and Student's $t$ test used to test for statistically significant differences in the latency, $\mathrm{p}-\mathrm{pV}$, and area of MUs grouped according to rank order of activation.

\section{LATENCY CALCULATIONS}

Another test of the relationship between motor unit size and latency that included larger numbers of MUs was to adjust the latencies of MUs activated at multiple points to a standard distance of $200 \mathrm{~mm}$. The latency from stimulation to motor unit discharge includes time delays in motor axon preterminal and terminal conduction and neuromuscular transmission. This 'residual 
latency' in the median and ulnar nerves of control subjects, has been experimentally determined to be $2.0 \mathrm{~ms}$ in this laboratory (cf. Hodes et al., 1948). The relative contribution of the residual latency is obviously much larger for points closer to the motor point and therefore the terminal latencies of single MUs have been adjusted by a correction factor:

$$
\begin{gathered}
\text { (Latency in } \mathrm{ms}-2.0 \mathrm{~ms}) \times \frac{0}{02 \mathrm{~d}}+2 \mathrm{~ms} \\
=\text { Adjusted latency }
\end{gathered}
$$

$\mathrm{d}=$ distance in $\mathrm{mm}$ from point of activation to motor point

\section{COLLISION EXPERIMENT}

In testing for overlap in the motor axons excited at two separate points along the length of a nerve, the method of collision was used. The stimulation points on the motor nerve were at least $200 \mathrm{~mm}$ apart and at each point the stimulus intensity increased until the muscle compound potential was $20 \%$ of the maximum compound potential. If the order of excitement of axons at the two points was random, impulse collision could be expected to occur in approximately $4 \%$ $(0.20 \times 0.20)$ of the axons and the compound potential evoked by the second and more proximal stimulus reduced by a similar margin compared with the potential evoked by the initial distal stimulus. Significantly larger reductions in the second evoked muscle compound potential would point to more than the expected overlap in the motor axons activated at the two levels and could be taken to mean that certain motor axons have preferentially lower thresholds.

\section{COMPUTATION OF MEAN MOTOR UNIT POTENTIAL (MMUP)}

The peak voltages of motor units activated at one point are not temporaly coincident because of variations from unit to unit in the latencies from stimulation to initial MU deflection $\left(\mathrm{L}_{1}\right)$ and from the latter to the peak voltage $\left(\mathrm{L}_{2}\right)$. This fact makes it impossible to compare the means of the maximum p-p voltages of motor units using MPS or isometric contraction, with the mean MMUP obtained using the conventional method (McComas et al., 1971) or the method incorporating a correction for alternation (Milner-Brown and Brown, 1976). The last two methods automatically incorporate such variations in the latencies in the motor unit potential summation. It is clearly not possible to make corrections for the differences in $\mathrm{L}_{1}$ for MUs isolated by MPS but differences in $\mathrm{L}_{2}$ from one $\mathrm{MU}$ to another can be corrected partially by making the assumption that the $L_{1}$ latencies are identical for all MUs and calculating the maximum $p-p$ voltage sum of the single MUs isolated.

\section{RESULTS}

The original purpose of this investigation was to test the method of multiple point stimulation as an alternative means of obtaining a larger and more representative sample of MUs for estimating the mean motor unit potential. Only the first section of the results will be concerned with this study; subsequent sections will be devoted to the rank order of recruitment of MUs during graded electrical stimulation and the extent of axon branching, which evolved as the major parts of this investigation.

\section{MEAN MOTOR UNIT POTENTIAL (MMUP)}

In this investigation 'all' or 'nothing' discharges $\vec{\circ}$ from more than one motor unit occurred a 50 motor threshold in $20-30 \%$ of the points stimu夰 $\omega$ lated in controls. Table 1 illustrates the fre $\frac{\text { Dे }}{3}$ 의

\section{T A B L E 1}

PERCENTAGE OF TOTAL NUMBER OF STIMULATION SITES AT WHICH $1, \ldots$ n MUS EXCLUSIVE OF ALTERNATION COULD BE OBTAINED (SITES WHERE ALTERNATION OCCURRED AT MOTOR THRESHOLD NOT INCLUDED)

\begin{tabular}{ccccccc}
\hline Groups & $n=1$ & $n=2$ & $n=3$ & $n=4$ & $n=5$ & $n=6$ \\
\hline $\begin{array}{c}\text { Median and ulnar } \\
\text { control(169) }\end{array}$ & 32 & 27 & 26 & 10 & 4 & 1 \\
Pathological(108) & 31 & 22 & 26 & 16 & 5 & 0 \\
\hline
\end{tabular}

Total number of stimulation sites in parentheses.

quencies of obtaining only $1,2,3 \ldots \mathrm{n}$ motor units, exclusive of alternation, at stimulation points in both median and ulnar nerves. At no point could more than six MUs be obtained exclusive of alternation and in only $15 \%$ (control) and $21 \%$ (pathological) of the points could more than three motor units be so obtained. The control hypothenar MMUP calculated from the first MU activated only at each point was $0.049 \pm$ $0.03 \mathrm{MV}$; this was significantly smaller than $0.077 \pm 0.030 \mathrm{mV}(\mathrm{P}<0.02)$ if all MUs activated at each point, exclusive of alternation, are included. 
In the median control and median and ulnar pathological groups the MMUP of all MUs exclusive of alternation, was likewise larger than the MMUP of only the first MUs activated. To test how representative the MUs obtained by MPS were, a direct comparison was made with the MUs isolated using the isometric voluntary contraction method (Milner-Brown et al., 1973a) with the surface electrodes in the same location. In both median and ulnar nerves, MUs could be recruited at high force levels, larger than MUs that could be recruited by MPS. For example, the histogram in Fig. 2A illustrates that all motor units recruited from hypothenar muscles by MPS were less than $0.250 \mathrm{mV} p-p V$, most being less than $0.100 \mathrm{mV} \mathrm{p}-\mathrm{pV}$. Using isometric contraction, by contrast, $24 \%$ of the motor units were larger than $0.300 \mathrm{mV} \mathrm{p}-\mathrm{pV}$ and only $41 \%$ less than $0.100 \mathrm{mV}$ (Fig. 2B).

The above results are contrary to those obtained in the preliminary study (Brown and MilnerBrown, 1976), and thus eliminate MPS as a potential method for obtaining a more representative mean motor unit potential and a more accurate motor unit estimate. The rest of the paper deals with results pertaining to the rank order of recruitment of MUs and the extent of axonal branching using multiple point stimulation of peripheral nerves.

\section{RANK ORDER OF RECRUITMENT OF MOTOR UNITS}

From the beginning of this investigation it was observed that the latency, area, and $\mathrm{p}-\mathrm{pV}$ of MUs were related to the rank order of activation by the electrical stimulus. Graded stimulation at each point excited first, small motor units that had long latencies, progressive increases in the stimulus intensity activating increasingly large motor units having shorter latencies (Fig. 3). As described in the Methods Section, pairs of MUs in each set were ranked in the order of activation and compared with the ranked order of increasing $\mathrm{p}-\mathrm{pV}$ of decreasing latency. The positive and negative scores obtained in the ulnar control and pathological groups are summarised in Tables $2 \mathrm{~A}$ and $\mathrm{B}$. The results indicate a statistically significant correlation $(\mathrm{P}<0.01)$ between increasing $\mathrm{p}-\mathrm{pV}$, decreasing latency, and the rank order of recruitment of MUs in each set as well as in combined sets, except the two unit set of the pathological group. In the median nerve groups, however, the corresponding correlations were not statistically significant in the two and three unit sets, but the combined sets showed statistical significance $(P<0.01)$. The reason for this dif- ference between ulnar and median groups is not apparent.

The data were further analysed statistically by correlating the mean $p-p V$ of the first 1-3 MUs activated with the rank order of activation. The results obtained from the ulnar and median control groups summarised in the form of a histogram, in Fig. 4A, B, were statistically significant $(P<0.05)$. In the pathological groups similar rank order of recruitment was observed, except that the MUs recruited had larger p-pV (Fig. 5) (Table 3 ). Both methods therefore provided statistically significant support that graded electrical stimula-
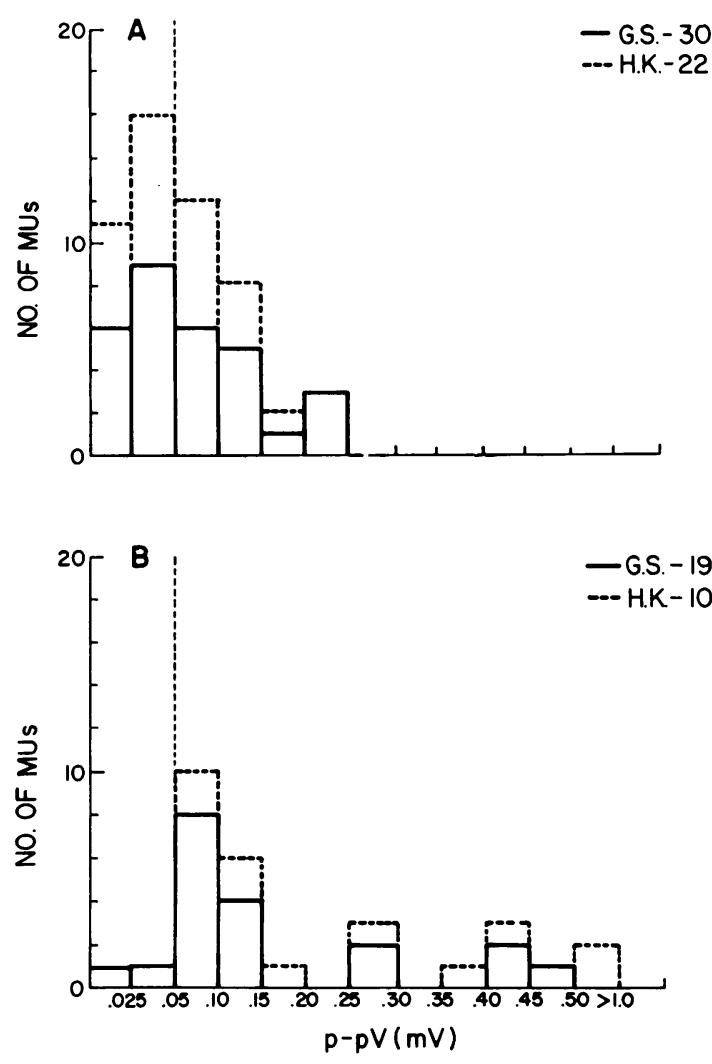

FIG. 2 Histograms of $(A)(p-p) V$ of $M U$ s isolated from hypothenar muscles of two control subjects using multiple point stimulation and $(B)(p-p) V$ of MUs isolated from the same subjects using the isometric voluntary contraction method with the surface electrodes in the same location. The broken lines at $0.05 \mathrm{mV}$ emphasise the fact that the first two divisions on the abscissa are $0.025 \mathrm{mV}$, while subsequent divisions are $0.05 \mathrm{mV}$. 


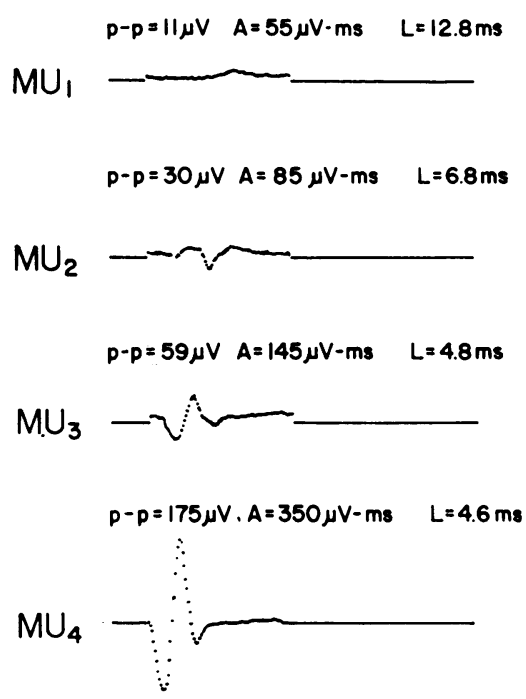

FIG. 3 Four consecutive MUs obtained by graded electrical stimulation (exclusive of alternation) at a single site over the ulnar nerve of one of the pathological ulnars. $M U_{1}$ had the lowest threshold and $\mathrm{MU}_{4}$ the highest threshold. The waveforms are the absolute configuration of the $M U s$ as displayed digitally on the averager, with the parameters of each unit above: $p-p=$ peak-topeak voltage, $A=$ area, $L=$ latency.

\section{T A B L E 2}

PAIR SCORES OBTAINED BY COMPARING RANKED ORDER OF INCREASING P-PV AND OF DECREASING LATENCY WITH RANKED ORDER OF ACTIVATION OF MUS IN ULNAR CONTROL AND PATHOLOGICAL GROUPS

\begin{tabular}{|c|c|c|c|c|c|}
\hline \multirow{3}{*}{$\begin{array}{c}M U \text { set } \\
(N o .)\end{array}$} & \multirow{3}{*}{ Group } & \multicolumn{4}{|c|}{ Pair scores } \\
\hline & & \multicolumn{2}{|c|}{ Increasing $p-p V$} & \multicolumn{2}{|c|}{ Decreasing latencies } \\
\hline & & + & - & + & - \\
\hline 2 & $\begin{array}{r}C(21) \\
\text { Path (12) }\end{array}$ & $\begin{array}{l}17 \\
8^{*}\end{array}$ & $\begin{array}{l}4 \\
4\end{array}$ & $\begin{array}{l}15 \\
8.5^{*}\end{array}$ & $\begin{array}{l}3 \\
3.5\end{array}$ \\
\hline 3 & $\begin{array}{r}C(35) \\
\text { Path (17) }\end{array}$ & $\begin{array}{l}86 \\
37\end{array}$ & $\begin{array}{l}19 \\
14\end{array}$ & $\begin{array}{l}80 \\
36\end{array}$ & $\begin{array}{l}25 \\
15\end{array}$ \\
\hline 4 & $\begin{array}{c}C \text { (9) } \\
\text { Path (12) }\end{array}$ & $\begin{array}{l}40 \\
50.5\end{array}$ & $\begin{array}{l}14 \\
21.5\end{array}$ & $\begin{array}{l}38.5 \\
49\end{array}$ & $\begin{array}{l}15.5 \\
23\end{array}$ \\
\hline 5 & Path (3) & 21.5 & 8.5 & 20 & 10 \\
\hline All & $\begin{array}{r}C(70) \\
\text { Path (44) }\end{array}$ & $\begin{array}{l}143 \\
117\end{array}$ & $\begin{array}{l}37 \\
48\end{array}$ & $\begin{array}{l}135 \\
113.5\end{array}$ & $\begin{array}{l}45 \\
51.5\end{array}$ \\
\hline
\end{tabular}

$P=0.01$ for individual and combined sets.

* $P=0.05$.

Path: Pathological.

C: Control.

Number of sets in parentheses. tion does activate progressively larger motor units. The MU size was determined using both the $\mathrm{p}-\mathrm{pV}$ and area of the surface evoked potentials; only values of $\mathrm{p}-\mathrm{pV}$ are given because statistical analyses using areas gave the same results.

\section{MOTOR UNIT LATENCIES}

In order to relate the conduction times to the area and $\mathrm{p}-\mathrm{pV}$ of MUs, an adjustment of the latency of MUs activated at different points along the length of the nerve to a standard distance from stimulation to motor point was necessary (see Methods Section). The adjusted latencies plotted against $\mathrm{p}-\mathrm{pV}$ in one control and one ulnar pathological subject are illustrated in Figs. 6 and 7 . Such plots provide a quantitative means of relating motor unit sizes with their conduction velocities which are inversely proportional to latencies. In general, the larger motor units always had short latencies and the longest latency motor units were invariably small. Between the above two groups were other units having little correlation between $\mathrm{p}-\mathrm{pV}$ or area and latency This suggested that within the motor unit population, most of the intermediate and small motor units had conduction velocities and hence, probably, axon diameters that fell within a fairly narrow distribution. The much longer latency small MUs probably had correspondingly smaller fibre diameters and conversely the large MUs? having short latencies probably had large fibre diameters.

\section{MU SIZES: DISTAL $v s$ PROXIMAL STIMULATION}

If significant branching is present in normal motor axons in the forearm segment, an expected result could be that the mean $\mathrm{p}-\mathrm{pV}$ or area of units excited at distal points would be less than that of units excited at more proximal locations because a proportion of the axons excited at more distal points would be branches of the proximal axon. Table 4 illustrates that, in both control groups, the mean p-p voltages of $\mathrm{MU}_{1}$, $\mathrm{MU}_{2}$, and $\mathrm{MU}_{3}$ proximal to the elbow were larger comparable voltages of units excited distally in the forearm. The results were statistically significant only in the case of $\mathrm{MU}_{2}$ and $\mathrm{MU}_{3}$ (ulnar) and $\mathrm{MU}_{1}$ (median). In others, the wide range in $p-p$ voltages, reflected in the large standard deviations and small sample sizes, probably accounted for the lack of significant differences in the sizes of MUs activated at distal and proximal points. 

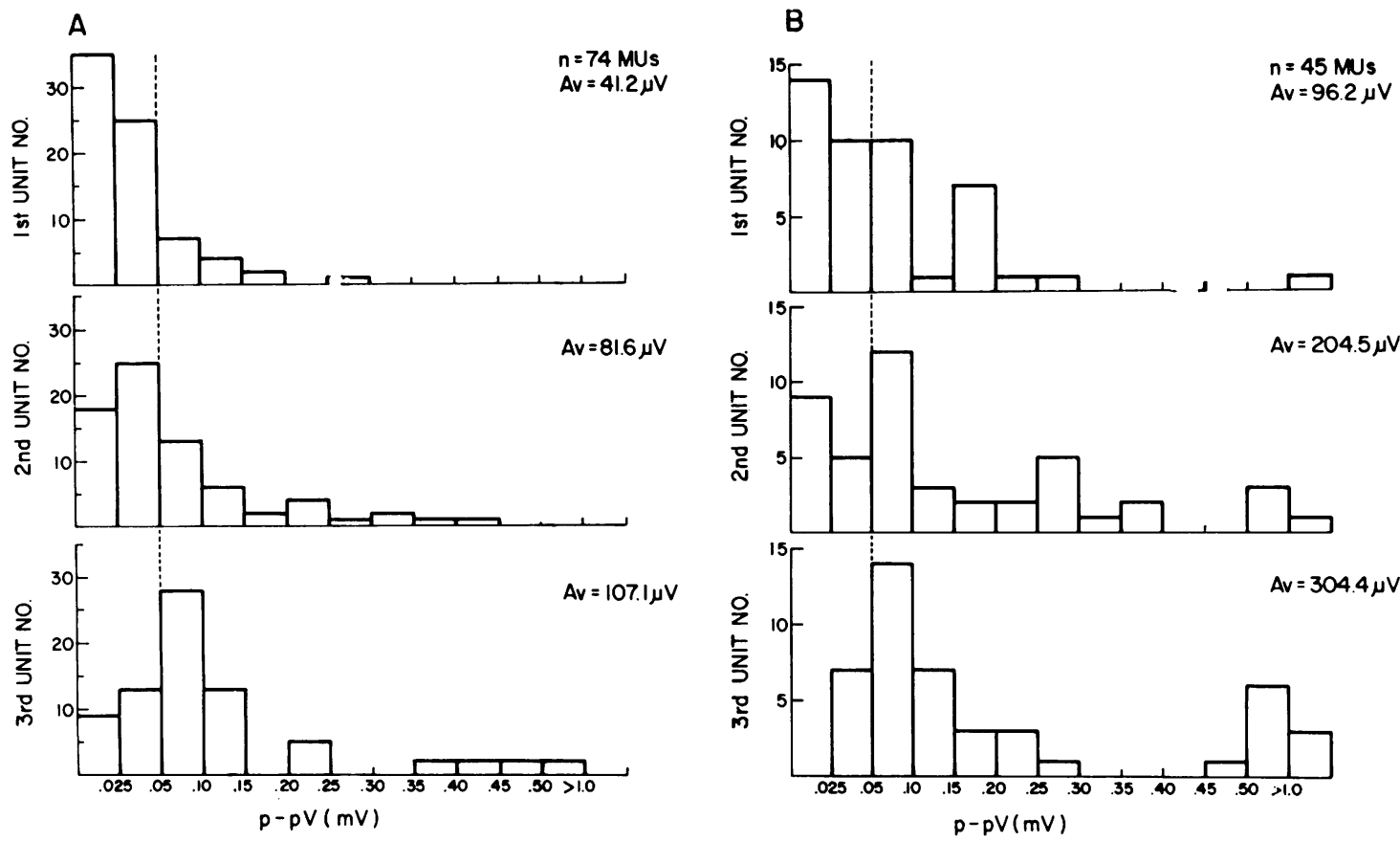

FIG. 4 Histogram of $(p-p) V$ of MUs recruited first, second, and third at a stimulation site of $(A)$ ulnar $(B)$ median control groups. The broken lines emphasise the fact that the first two divisions on the abscissa are $0.025 \mathrm{mV}$, while subsequent divisions are $0.05 \mathrm{mV}$ up to $0.5 \mathrm{mV}$. The correlation between the average $p-p V$ of the MUs and the rank order of activation was statistically significant $(\mathrm{P}<0.05)$.

T A B LE 3

PAIR SCORES OBTAINED BY COMPARING RANKED ORDER OF INCREASING P-PV AND OF DECREASING LATENCY WITH RANKED ORDER OF ACTIVATION OF MUS IN MEDIAN CONTROL AND PATHOLOGICAL GROUPS

\begin{tabular}{|c|c|c|c|c|c|}
\hline \multirow{3}{*}{$\begin{array}{l}\text { MU set } \\
\text { (No.) }\end{array}$} & \multirow{3}{*}{ Group } & \multicolumn{4}{|c|}{ Pair scores } \\
\hline & & \multicolumn{2}{|c|}{ Increasing $p-p V$} & \multicolumn{2}{|c|}{ Decreasing latency } \\
\hline & & + & - & + & - \\
\hline 2 & $\begin{array}{r}\mathrm{C}(20) \\
\text { Path (13) }\end{array}$ & $\begin{array}{l}14^{*} \\
8^{*}\end{array}$ & $\begin{array}{l}6 \\
5\end{array}$ & ${ }_{9}^{11^{*}}$ & $\begin{array}{l}9 \\
4\end{array}$ \\
\hline 3 & $\begin{array}{r}C(14) \\
\text { Path (12) }\end{array}$ & $\begin{array}{l}30 \\
21^{*}\end{array}$ & $\begin{array}{l}12 \\
15\end{array}$ & $\begin{array}{l}24.5^{*} \\
19.5^{*}\end{array}$ & $\begin{array}{l}17.5 \\
16.5\end{array}$ \\
\hline 4 & $\begin{array}{r}C(6) \\
\text { Path (6) }\end{array}$ & $\begin{array}{l}26 \\
24\end{array}$ & $\begin{array}{l}10 \\
12\end{array}$ & $\begin{array}{l}21.5^{*} \\
29.5\end{array}$ & $\begin{array}{r}14.5 \\
6.5\end{array}$ \\
\hline 5 & $\begin{array}{r}\text { C (4) } \\
\text { Path (3) }\end{array}$ & $\begin{array}{l}35 \\
23\end{array}$ & $\begin{array}{l}5 \\
7\end{array}$ & $\begin{array}{l}32 \\
20.5\end{array}$ & $\begin{array}{l}8 \\
9.5\end{array}$ \\
\hline All & $\begin{array}{r}C(45) \\
\text { Path (34) }\end{array}$ & $\begin{array}{r}105 \\
76\end{array}$ & $\begin{array}{l}33 \\
39\end{array}$ & $\begin{array}{l}89 \\
78.5\end{array}$ & $\begin{array}{l}49 \\
36.5\end{array}$ \\
\hline
\end{tabular}

$P=<0.01$ for individual and combined sets. $P^{*} 70.1$.

\section{COLLISION EXPERIMENT}

Substantial overlap in the motor axons excited at two separate points was suggested by the results of the collision experiments. In 19 combined median and ulnar nerves a $30 \pm 14$ one SD per cent reduction in the $\mathrm{p}-\mathrm{pV}$ of the compound muscle potential evoked by the second proximal stimulus was observed. Figure 8 is an example of such a collision investigation. The reduction of compound muscle potential was much more than the expected $4 \%$ if motor axons at the two points had been excited at random. The observations suggest that many of the same axons have been preferentially excited at both points.

The foregoing collective evidence that electrical stimulation of motor nerves preferentially activated certain axons, in particular, axons of small motor units first and progressively larger units as the intensity of the stimulus is increased, was reinforced by the observation that the largest motor units could not be activated by near thres- 


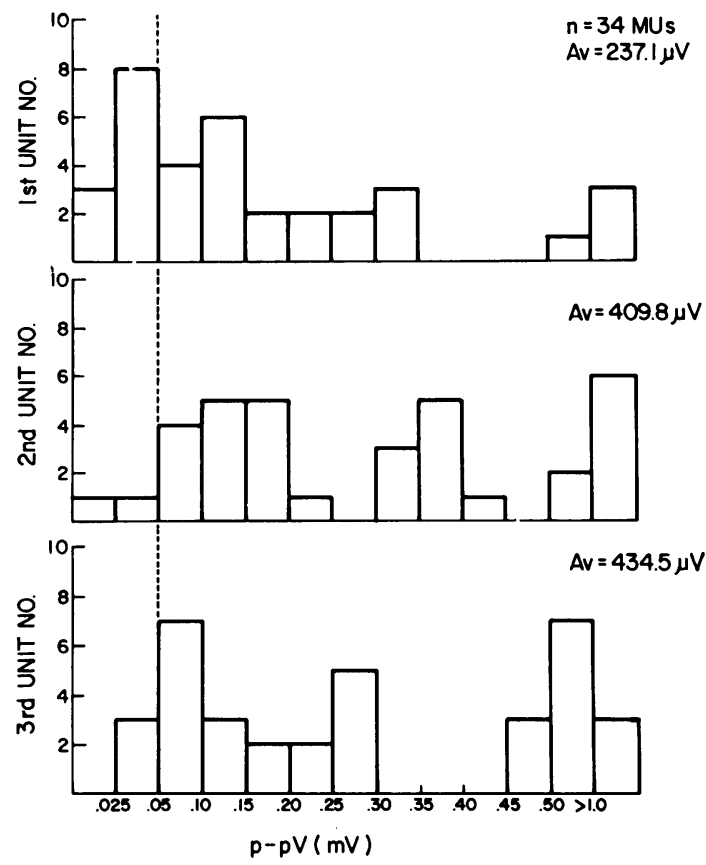

FIG. 5 Histogram of $(p-p) V$ of $M U s$ recruited first, second, and third at a stimulation site of the median pathological group. The correlation between the average $p-p V$ of $M U_{1}$ and $M U_{2}$ and the rank order of activation was statistically significant $(\mathrm{P}<0.05)$.

hold stimulation. This latter finding was supported in the present investigation by direct comparison of motor units isolated by isometric contraction versus motor units isolated by MPS (Fig. 2).

As in the first dorsal interosseous muscle, the $\mathrm{p}-\mathrm{pV}$ correlated with the twitch tension and threshold force at which the unit was activated in the abductor digiti minimi muscle (Fig. 9). The clear relation between the $\mathrm{p}-\mathrm{pV}$ and twitch tension of the units in the abductor digiti minimi strongly supported the assumption clearly inherent in the previous observations that motor units of small $\mathrm{p}-\mathrm{pV}$ and area are the voltage and voltage-time analogues of motor units generating little force, whereas large surface voltage and area units generated larger tensions.

\section{DISCUSSION}

The most important observation in this investigation has been that motor units are recruited in an orderly pattern, from small to large by graded increases (before alternation) in the electrical stimulus delivered to a motor nerve in man. The correlations between the rank order of activation and peak-to-peak voltage and area of the evoked muscle potentials were significantly high in all normal subjects as well as in patients with entrapment neuropathies. In addition, the motor units activated at higher stimulus intensities always had short latencies, which could be interpreted as characteristic of large motor axons with fast conduction velocities. In view of the homogeneous character of motor units, the latter data lend further support to the fact that the motor units with large evoked muscle potentials were truly large motor units. Furthermore, the collision which occurred between impulses generated by submaximal stimuli at two separate points along the length of the nerve was much higher than would be expected by chance alone. Close to onethird of the motor axons excited at one point could also be excited at the second point. Activation of the identical motor unit at points $200 \mathrm{~mm}$ or more apart occurred $2-5 \%$ of the time, a percentage much higher than could be expected if the motor excitabilities and fibre positions were random (less than $1 / 10^{5}$, assuming 200 motor axons in the nerve).

The degree of overlap could be interpreted to mean that the relative position of nerve fibres with respect to the surface stimulating electrode was much the same at points along the length of the nerve $200 \mathrm{~mm}$ or more apart, or possibly that the stimulation selectivity activated many of the same fibres at the two levels because the fibres had inherently higher excitabilities than other fibres. It is quite likely that both factors, position and absolute excitability, combined to determine the particular fibres activated at any point, a conclusion supported by the complementary fact that collision did not occur in close to two-thirds of the fibres activated at the two points in the collision experiments.

The rank order of the excitabilities of motor unit to nerve stimulation received further support by the apparent exclusion of large motor units of threshold stimulation. Comparison of the sizes of motor units isolated by MPS with units isolated using isometric contraction showed that larger motor units recruited at high force levels were not included in the sample of motor units using MPS. The collective evidence can best be interpreted by the conclusion that the 'size principle' previously accepted using other methods of activation in humans (Milner-Brown et al., 


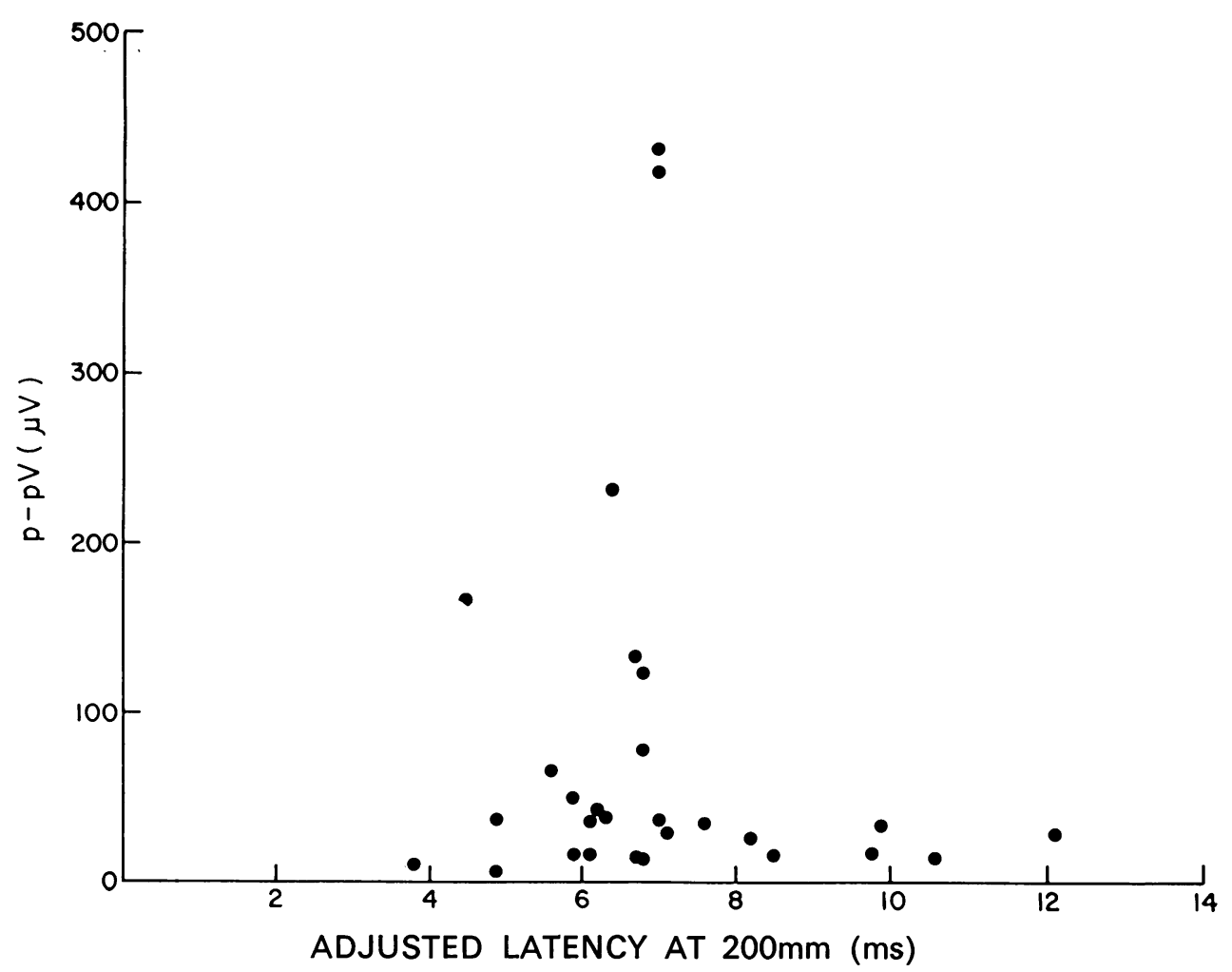

FIG. $6(p-p V) V$ as a function of 'adjusted latency' of MU's recruited from a single median control subject. The adjusted latency $=($ actual latency $(m s)-2 m s) \times \frac{200}{d}+2 m s$. $d=$ distance in $\mathrm{mm}$ from point of stimulation to motor point. The figure illustrates the fact that the latencies of the large units are always short, while longer latency units are invariably small.

1973b; Freund et al., 1975) and animals (Henneman and Olson, 1965; Henneman et al., 1965; Burke, $1967,1968 \mathrm{a}, \mathrm{b}$ ) is applicable also to nerve stimulation.

The rank order of activation observed in this investigation would not have been expected because of the more traditional view that the largest fibres having the fastest conduction velocities are first activated by brief stimulus pulses (Erlarger and Gasser, 1937). The latter evidence was based on the relative excitabilities of fibre groups in the compound action potential of cutaneous nerves and supported by evidence that the current required to excite single myelinated fibres is less for larger than for the smaller diameter fibres (Tasaki, 1953). In the latter report, however, little correlation between excitability and fibre size was present in fibres over $10 \mu \mathrm{m}$ in diameter. Also no evidence to date had established that in nerve fibres of uniform functional type, for example motor axons, excitability was related to motor unit size. In the extensor digitorum communis muscle of the baboon, no relation between the conduction velocity and twitch tension of motor units of that muscle was observed (Eccles et al., 1968).

In man, using surface stimulation, it has been reported that the first motor units activated have longer latencies than the maximum compound potential (Hodes et al., 1965; Bergmans, 1970). Moreover, the largest motor units that can be isolated using the $F$ recurrent discharge technique have been isolated at stimulus intensities much above motor threshold (Feasby and Brown, 1974). 


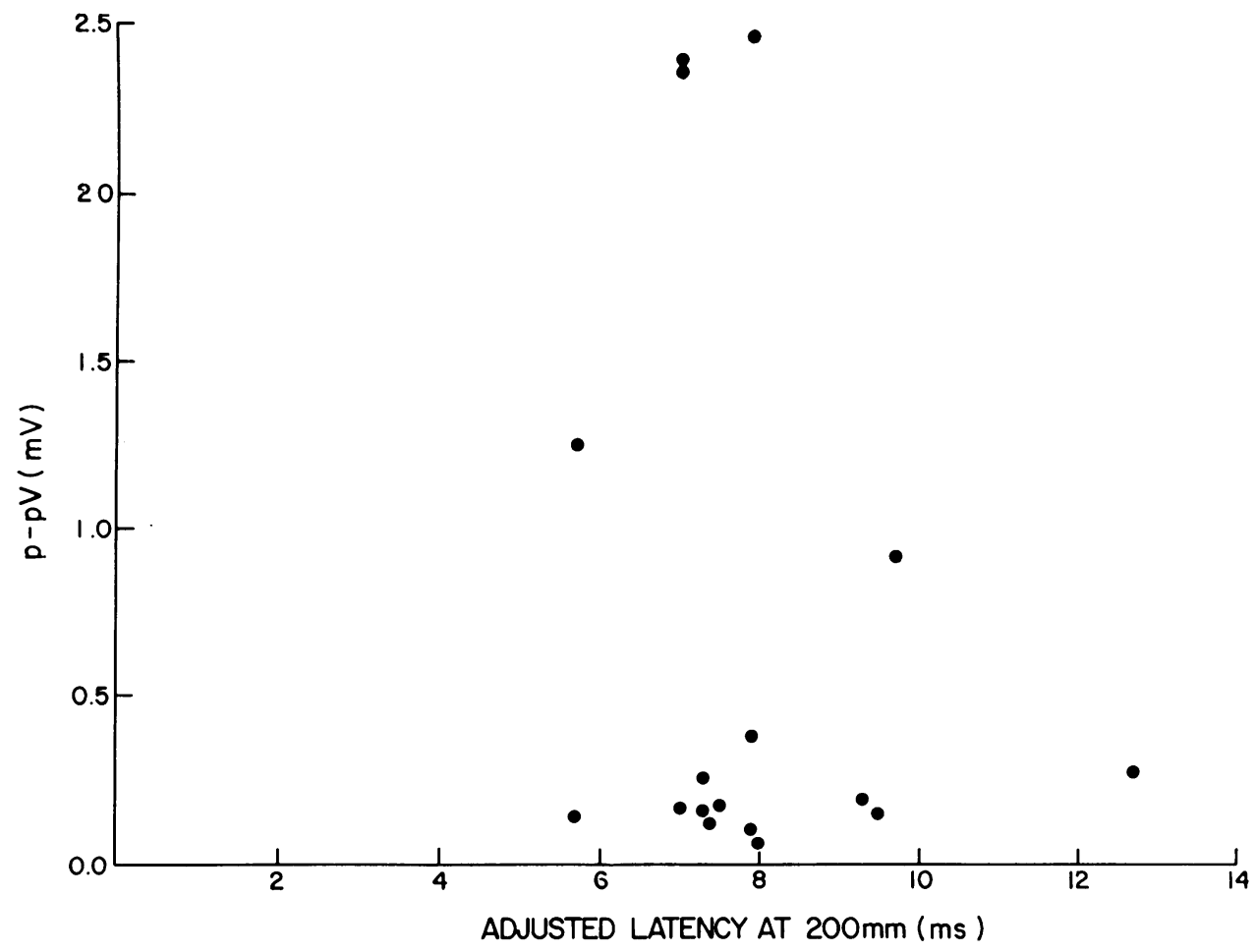

FIG. $7 \quad(p-p) V$ as a function of 'adjusted latency' of MUs recruited from a single median pathological subject. The adjusted latency $=($ actual latency $(m s)-2 m s) \times$ $\frac{200}{d}+2 \mathrm{~ms}$. $d=$ distance in $\mathrm{mm}$ from point of stimulation to motor point. The figure illustrates the fact that the latencies of the large units are always short, while longer latency units are invariably small.

T A B L E 4

COMPARISON OF MEAN p-pV OF MUS RECRUITED BY STIMULATING NERVE ABOVE AND BELOW ELBOW

\begin{tabular}{|c|c|c|c|c|c|c|}
\hline \multirow{2}{*}{$\begin{array}{l}\text { Stimulation } \\
\text { site }\end{array}$} & \multicolumn{3}{|c|}{$\begin{array}{c}\text { Ulnar controls } \\
\text { mean }(p-p) V \text { in } \mu V\end{array}$} & \multicolumn{3}{|c|}{$\begin{array}{c}\text { Median controls } \\
\text { mean }(p-p) V \text { in } \mu V\end{array}$} \\
\hline & $M U_{1}$ & $M U_{2}$ & $M U_{3}$ & $M U_{1}$ & $M U_{2}$ & $M U_{3}$ \\
\hline $\begin{array}{l}\text { Above } \\
\text { elbow }\end{array}$ & $\begin{array}{c}43.44 \\
(37)\end{array}$ & $\begin{array}{c}111+123 \\
(37)\end{array}$ & $\begin{array}{l}152 \pm 155 \\
(23)\end{array}$ & $\begin{array}{l}107 \pm 144 \\
(23)\end{array}$ & $\begin{array}{c}90+94 \\
(23)\end{array}$ & $\begin{array}{c}150 \div 156 \\
\text { (14) }\end{array}$ \\
\hline $\begin{array}{l}\text { Below } \\
\text { clbow }\end{array}$ & $\begin{array}{c}40 \pm 52 \\
(37)\end{array}$ & $\begin{array}{c}54+61 \\
(36)\end{array}$ & $\begin{array}{c}66 \pm 67 \\
(23)\end{array}$ & $\begin{array}{l}47 \pm 63 \\
(23)\end{array}$ & $\begin{array}{l}73: 90 \\
(23)\end{array}$ & $\begin{array}{c}106+171 \\
(14)\end{array}$ \\
\hline$P$ & NS & $<0.02$ & $<0.02$ & $<0.02$ & NS & NS \\
\hline
\end{tabular}

P: Statistical significance.

Total number of MUs in parentheses. 

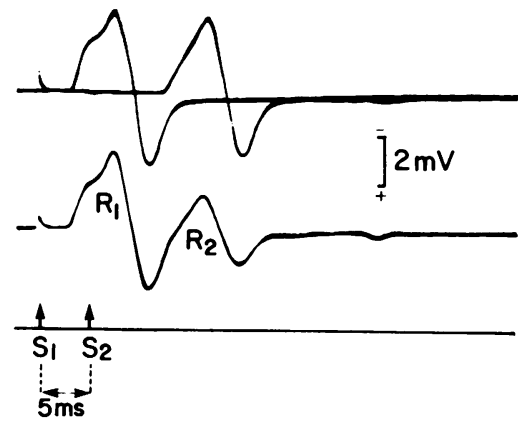

FIG. 8 Collision experiment: dual stimulations of the median and ulnar nerves were carried out at the wrist $\left(S_{1}\right)$ and at the elbow $\left(S_{2}\right) 5 \mathrm{~ms}$ later. Upper traces are compound potentials recorded from thenar muscles when $S_{1}$ and $S_{2}$ are applied separately. Lower trace shows compound potential due to $S_{1}$ alone $\left(R_{1}\right)$ and the compound potential when $S_{1}$ is followed $5 \mathrm{~ms}$ later by $S_{2}\left(R_{2}\right)$. The reduction in $R_{2}$ suggests that many of the same axons have been preferentially excited at both points of stimulation.

An earlier report using galvanic stimulation (Kugelberg and Skoglund, 1946) reported that ramp, long duration, increases in the stimulus intensity first activated small motor units, possibly the result of greater accommodation in the larger myelinated fibres. The latter interpretation could not explain the order of excitabilities in the present investigation or the reports of Bergmans (1970) or Hodes et al. (1965) that utilised brief stimulus pulses (1.0 ms or less). On the basis of this investigation it is not possible to determine the exact contribution of the anatomical arrangement of motor axons in a nerve to the order of excitabilities of nerve fibres.

In the case of extracellular current stimulation, the current necessary to excite a fibre could be expected to be inversely proportional to the external longitudinal resistance between nodes, in turn proportional to the internode length (Mountcastle, 1974), a factor that alone would account for the higher excitability of the larger diameter nerve fibres having longer internode lengths. Other factors, however, are likely to be important including the nodal resistance and area. In fact, the input resistance of smaller diameter fibres could be expected to be higher, a factor that could reduce the amount of external current required to excite the fibre.

It was important to establish that the large
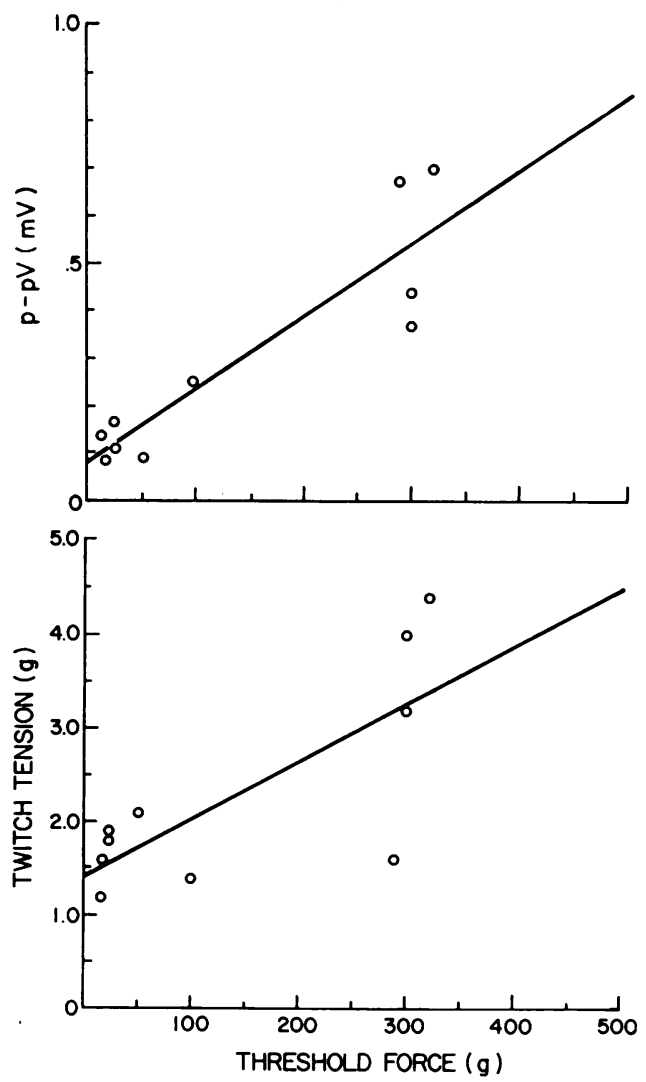

FIG. 9 Twitch tension and $p-p V$ as a function of the threshold force for recruiting $M U s$ in the abductor digiti minimi muscle of a control subject, during isometric voluntary contraction. The linear correlation coefficients of 0.8 and 0.6 respectively, were statistically significant $(\mathrm{P}<0.01$ and 0.05).

surface motor units generated more force than motor units of less $p-p$ voltage and area. The relationship between surface voltage and force has been established in the first dorsal interosseous muscle (Milner-Brown and Stein, 1975). In the present context this relationship between the p-p voltage and twitch tension of hypothenar motor units has also been observed. Moreover, large $\mathrm{p}-\mathrm{pV}$ and area motor units had short latencies (Figs. 6, 7) and an inverse relationship between relative latency and twitch tension has been reported by Freund et al. (1975). Therefore, it was feasible to assume that the rank order of activation from small to large $\mathrm{p}-\mathrm{pV}$ and area motor units by graded increases in the stimulus intensity 
was likely to be true also for twitch tension. Unfortunately, the twitch tensions of motor units using the MPS method could not be measured properly because of the complex of vectors of the direction of action of single motor units in the hypothenar and thenar muscle groups.

Motor unit potentials excited in an all-ornothing manner by electrical stimulation at points along the nerve can be considered to correspond to complete motor units only if no axon branching proximal to the point of nerve stimulation is present. Axon branching, if present, could mean that stimulation at points distal to the branching would excite fractions of single motor units corresponding to the all or nothing discharge of individual axon branches and could account in part for the apparent exclusion of large motor units by nerve stimulation.

Axon branching in healthy nerve based on investigations of axon reflexes (Fullerton and Gilliat, 1965) and anatomical investigations in animals (Eccles and Sherrington, 1930; Wray, 1969) has been considered to be unlikely at points $100 \mathrm{~mm}$ or more proximal to the motor point. In the present investigation, motor units excited distal to the elbow were noted to be smaller compared with units activated proximal to the elbow, particularly in the ulnar nerve, an observation that could be interpreted to mean that axon branching is present in the forearm much more than $100 \mathrm{~mm}$ proximal to the motor points. Even if so, such axon branching could have been the result of subclinical damage to the ulnar nerve as described by Neary et al. (1975). One important consequence of such branching could be that measurements of the parameters of motor units isolated by stimulation distal in the forearm could represent axon subunits and not motor units.

In conclusion, it should be reiterated that the original impetus in previous investigations had been to develop a non-painful method, acceptable to patients but accurate enough to quantitate the number of motor units in muscles. Such a test is important in order to quantitate changes in motor unit numbers in disease and to provide evidence of motor nerve damage in diseases of muscle and nerve. The present results, together with those previously published, suggest that, unfortunately, no method has been found to be entirely acceptable, even though some of the data obtained have helped in quantifying the extent of functional derangement in certain neuromuscular disorders.
Dr H. S. Milner-Brown is a Muscular Dystrophy Association of Canada Post-doctoral Fellow. We wish to thank all the hospital staff who served as controls. Ms Gisele St Pierre for typing the manuscript, Mr George Moogk for the illustrations, and Mr Michael Donnelly for photography.

\section{REFERENCES}

Ballantyne, J. P., and Hansen, S. (1974). A new method for the estimation of the number of motor units in a muscle. Journal of Neurology, Neurosurgery, and Psychiatry, 37, 907-915.

Bergmans, J. (1970). The Physiology of Single Human Nerve Fibers. Vander: Louvain.

Brown, W. F. (1972). A method for estimating the number of motor units in thenar muscles and the changes in motor unit count with ageing. Journal of Neurology, Neurosurgery, and Psychiatry, 35, 845-852.

Brown, W. F. (1973). Thenar motor unit count estimates in the carpal tunnel syndrome. Journal of Neurology, Neurosurgery, and Psychiatry, 36, 194-198.

Brown, W. F., and Milner-Brown, H. S. (1976). Some electrical properties of motor units and their effects on the methods of estimating motor unit numbers. Journal of Neurology, Neurosurgery, and Psychiatry, 39, 249-257.

Brown, W. F., Milner-Brown, H. S., and Drake, J. (1974). Errors in motor unit estimates. Proceedings of the Third International Congress on Muscle Diseases. Newcastle upon Tyne, 15-21 Sept. 1974. Excerpta Medica: Amsterdam.

Burke, R. E. (1967). Motor unit types of cat triceps sural muscle. Journal of Physiology, 193, 141-160.

Burke, R. E. (1968a). Group Ia synaptic input to fast and slow twitch motor units of cat triceps surae. Journal of Physiology, 196, 605-630.

Burke, R. E. (1968b). Firing pattern of gastrocnemius motor units in the decerebrate cat. Journal of Physiology, 196, 631-654.

Eccles, R. M., Phillips, C. G., and Wu Chien-ping (1968). Motor innervation motor unit organization and afferent innervation of muscle extensor digitorum communis of the baboon's forearm. Journal of Physiology, 198, 179-192.

Eccles, J. C., and Sherrington, C. S. (1930). Numbers of contraction values of individual motor units examined in some muscles of the limb. Proceedings of the Royal Society B, 106, 326-357.

Erlanger, J., and Gasser, H. S. (1937). Electrical Signs of Nervous Activity. University of Pennsylvania Press: Philadelphia.

Feasby, T. E., and Brown, W. F. (1974). Variations of motor unit size in the human extensor digitorum 
brevis and thenar muscles. Journal of Neurology, Neurosurgery, and Psychiatry, 37, 916-926.

Freund, H. J., Budingen, H. J., and Dietz, V. (1975). Activity of single motor units from human forearm muscles during voluntary isometric contractions. Journal of Neurophysiology, 38, 933-946.

Fullerton, P. M., and Gilliatt, R. W. (1965). Demonstration of axon reflexes in human motor nerve fibres. Journal of Neurology, Neurosurgery, and Psychiatry, 28, 1-11.

Henneman, E., and Olson, C. B. (1965). Relations between structure and function in the design of skeletal muscles. Journal of Neurophysiology, 28, 581-598.

Henneman, E., Somjen, G., and Carpenter, D. O. (1965). Excitability and inhibitability of motoneurons of different sizes. Journal of Neurophysiology, 28, 599-620.

Hodes, R., Gribetz, I., Moskowitz, J. A., and Wagman, I. H. (1965). Low threshold associated with slow conduction velocity. Archives of Neurology (Chic.), 12, 510-526.

Hodes, R., Larrabee, M. C., and German, W. (1948). The human electromyogram in response to nerve stimulation and the conduction velocity of motor axons. Archives of Neurology and Psychiatry, 60, 340-365.

Kendall, M. G. (1962). Rank Correlation Methods. Hafner: New York.

Kugelberg, E., and Skoglund, C. R. (1946). Natural and artificial activation of motor units-a comparison. Journal of Neurophysiology, 9, 399-412.

McComas, A. J., Fawcett, P. R. W., Campbell, M. J., and Sica, R. E. P. (1971). Electrophysiological estimation of the number of motor units within a human muscle. Journal of Neurology, Neurosurgery, and Psychiatry, 34, 121-131.

Milner-Brown, H. S., and Brown, W. F. (1976). New methods of estimating the number of motor units in a muscle. Journal of Neurology, Neurosurgery, and Psychiatry, 39, 258-265.

Milner-Brown, H. S., and Stein, R. B. (1975). The relation between the surface electromyogram and muscular force. Journal of Physiology, 246, 549569.

Milner-Brown, H. S., Stein, R. B., and Yemm, R. (1973a). The contractile properties of human motor units during voluntary isometric contractions. Journal of Physiology, 228, 285-306.

Milner-Brown, H. S., Stein, R. B., and Yemm, R. (1973b). The orderly recruitment of human motor units during voluntary isometric contractions. Journal of Physiology, 230, 359-370.

Mountcastle, V. B. (1974). Medical Physiology, 13th edn., p. 66. Edited by V. B. Mountcastle. Mosby: St. Louis.

Neary, D., Ochoa, J., and Gilliatt, R. W. (1975). Subclinical entrapment neuropathy in man. Journal of the Neurological Sciences, 24, 283-298.

Panayiotopoulos, C. P., Scarpalezos, S., and Papapetropoulos, Th. (1974). Electrophysiological estimation of motor units in Duchenne muscular dystrophy. Journal of the Neurological Sciences, 23, 89-98.

Sica, R. E. P., McComas, A. J., Upton, A. R. M., and Longmire, D. (1974). Motor unit estimates in small muscles of the hand. Journal of Neurology, Neurosurgery, and Psychiatry, 37, 55-67.

Tasaki, I. (1939). Electric stimulation and the excitatory process in the nerve fiber. American Journal of Physiology, 125, 380-395.

Tasaki, I. (1953). Nervous Transmission. Thomas: Springfield, IIl.

Wray, S. H. (1969). Innervation ratios for large and small limb muscles in the baboon. Journal of Comparative Neurology, 137, 227-250. 
Fish's Schizophrenia 2nd Edition. Edited by M. Hamilton. (Pp. xvi + 212; illustrated; f5.85.) John Wright and Sons: Bristol. 1976.

In 1962 the late Frank Fish produced the first edition of this excellent little book. He drew on his own extensive experience, and on his wide knowledge of the German literature, to give a masterly account of the phenomenology and psychopathology of schizophrenia. The book has long been out of print. Now Professor Max Hamilton has produced a second edition. He has scarcely altered the clinical sections, but he has drastically revised and modernised the sections on aetiology and treatment. The result is a triumph, a second edition better than the first. Frank Fish would have been proud of it.

J. L. GIBBONS

Principles of Family Psychiatry By John G. Howells. (Pp. 338; £7.00.) Pitman Medical : Tunbridge Wells. 1976.

It is a large and potentially dangerous step from a position in which meticulous attention is given to the family and social environment of a person suffering from psychological problems to one in which 'the family is the focus and the individual an adjunct; the patient is the family'. In this book, Dr Howells presses his case for the latter orientation with the enthusiasm which one might expect from a pioneer. The book's strengths, however, are also its weaknesses. Clarity and force of expression too often become blinkered dogmatism; idiosyncratic viewpoints and terminology, however arresting and rational, too often ignore the contributions of other workers, and the unquestioned value of a focus on the family too often fails to take account of significant individual complexities.

As a personal coherent but eccentric statement of one man's view the book is interesting and valuable; as an organising statement of current themes in family psychiatry it cannot be regarded as adequate.

A C. MACFIE

Hyperactivity By D. M. Ross and S. A. Ross. (Pp. 385 ; illustrated ; $£ 13.75, \$ 23.00$.) John Wiley: Chichester. 1976.

The number of books published on the common and important problem of hyperactivity rose from one in the four year period $1950-53$ to 33 in the four year period 1970-73. This new volume must rank among the best available for its comprehensiveness, usefulness, and balance. The two authors have achieved a rare level of sophisticated discussion over a wide range of topics encompassing clinical, historical, educational, and research aspects of their subject. There is a masterly summary of historical and conceptual issues, including a succinct and illuminating section on minimal brain dysfunction, and the discussion of psychotherapy provides a carefully weighted and pragmatic account of both behaviour modification and more traditional approaches.

The book is well produced, and though the price might be deemed somewhat high even in the present financial climate, the investment will be well worth while for workers in the fields of child psychiatry and paediatrics; for others it is a model of careful and thoughtful presentation.

A. C. MACFIE

\section{Notices}

\section{Neurosurgery : a new journal}

Owned and sponsored by the Congress of Neurological Surgeons, Inc. and published by the Williams \& Wilkins Co., Neurosurgery will feature original papers from both clinical and experimental perspectives, case reports, book reviews, neurosurgical news, and solicited review articles on neurosurgical topics as well as those from related fields. Also included will be English abstracts from current foreign language journals, symposium abstracts, pertinent legislative developments, and a calendar of events of interest to the neurosurgeon. Neurosurgery will be published bimonthly, beginning in July 1977. For further information, contact: Dr Robert H. Wilkins, Editor, Neurosurgery, Box 3807, Duke University Medical Center, Durham, N.C. 27710, USA.

International congresses, 12-17 June 1977, Santiago, Chile

Eighth International Congress of Neurosurgical Nursing

International Symposium on Brain Death

Seventeenth Latin-American Congress of Neurosurgery

Secretary General: Dr L. Basauri
Tenth International Symposium on Neurological Sciences

Third Latin-American Colloquium of Paediatric Neurosurgery

Twelfth Latin-American Congress of Electroencephalography

President: Dr Nelly Chiofalo

The address of the secretariat for these congresses is: Casilla 3717, Santiago, Chile.

Eighth Latin-American Congress of Neuroradiology. President: Dr Mario Corrales. Address of secretariat: Marcoleta 347, Santiago, Chile.

International Society for Paediatric Neurosurgery

The schedule of annual meetings for the International Society for Paediatric Neurosurgery will be as follows:

1977 Guaruja, Brazil; Chairman of Annual Meeting: Machado de Almeida; Local Programme Chairmen: Raul Carrea and Luciano Basauri; 26-28 June 1977, Casa Grande Hotel, Guaruja, Brazil.

1978 Jerusalem, Israel (Hadassah Medical Organization); Committee Conference Chairman: Abraham Sahar.

1979 Chicago, Illinois (Northwestern University); Committee Conference Chairman: Anthony J. Raimond.

1980 Marseille, France; Committee Conference Chairman: Maurice Choux.

1981 New York, New York (New York University); Committee Conference Chairman: Joseph Ransohoff.

\section{Corrections}

In the abstract of a paper by J. Mohan, D. J. Boullin, and C. B. T. Adams on the effect of dopamine on human cerebral arteries (Proceedings of the Society of British Neurological Surgeons, fournal of Neurology, Neurosurgery, and Psychiatry, 39, 933) the first word of the second paragraph should read 'dopamine' and not 'histamine'.

In the paper by Kadrie et al. (1976), Journal of Neurology, Neurosurgery, and Psychiatry, 39, 973-985, there was an error in the formula on p. 976, line 9. This should read:

(Latency in ms $-2.0 \mathrm{~ms}$ ) $\times \frac{200}{\mathrm{~d}}+2 \mathrm{~ms}$ $=$ Adjusted latency

$\mathbf{d}=$ distance in $\mathrm{mm}$ from point of activation to motor point 